\title{
PAULO FREIRE: CONTRADISCURSO E PRÁTICA DE RESISTÊNCIA AO NEOCONSERVADORISMO NO CENÁRIO POLÍTICO E EDUCACIONAL BRASILEIRO
}

\author{
PAULO FREIRE: CONTRADISCOURSE AND PRACTICE OF RESISTANCE TO \\ NEOCONSERVATISM IN THE BRAZILIAN POLITICAL AND EDUCATIONAL \\ SCENARIO
}

\author{
(iD) Gabriela Costa Faval \\ Mestranda em Educação \\ Universidade do Estado do Pará - UEPA. \\ Belém, Pará - Brasil. \\ gabyfaval@gmail.com \\ Ivanilde Apoluceno de Oliveira \\ Doutora em educação \\ Universidade do Estado do Pará - UEPA. \\ Belém, Pará - Brasil. \\ nildeapoluceno@gmail.com
}

Resumo: O pensar e agir freireanos se tornam, mais uma vez, alvo de discursos que, longe da neutralidade, se posicionam no sentido de silenciar educadores e direcionar as práticas educativas para um distanciamento da democracia e da criticidade do ensino, sendo por isso necessário esclarecer o seu pensamento educacional, na perspectiva de um contradiscurso de resistência, evidenciando a sua importância na educação brasileira. A questão norteadora deste artigo é: quais as razões de Paulo Freire ser alvo de perseguições e críticas no atual contexto político? Objetiva-se analisar, na atual conjuntura brasileira, o pensamento de Paulo Freire enquanto contradiscurso de enfrentamento e resistência, contra os ataques à sua pessoa e proposta educacional, esclarecendo os seus pressupostos educacionais, refutando as críticas infundáveis e apontando a sua importância no cenário educacional brasileiro. Consiste em uma pesquisa bibliográfica que envolve as produções de Paulo Freire, mas também de resultados de pesquisas sobre a educação freireana. Destaca o caráter humanista e ético-político da educação de Paulo Freire, que não pode ser pensada como campo neutro, nem tampouco confundida com mera doutrinação partidária e apresenta a importância da educação freireana na educação brasileira.

Palavras-chave: contradiscurso de resistência; neo-conversadorismo; Paulo Freire.

\begin{abstract}
Freire's thinking and acting become, once again, the target of discourses that, far from neutrality, are aimed at silencing educators and directing educational practices towards a distance from democracy and the criticality of teaching, so it is necessary to clarify the educational thought, from the perspective of a resistance discourse, highlighting its importance in Brazilian education. The guiding question of this article is: what are the reasons for Paulo Freire being the target of persecution and criticism in the current political context? The objective is to analyze, in the current Brazilian conjuncture, Paulo Freire's thought as a counter-discourse of confrontation and resistance, against the attacks on his person and educational proposal, clarifying his educational assumptions, refuting the unfounded criticism and pointing out its importance in the educational scenario Brazilian. It consists of a bibliographical research that involves Paulo Freire's productions, but also results of research on Freire's education. It highlights the humanist and ethical-political character of Paulo Freire's education, which cannot be thought of as a neutral field, nor confused with mere party indoctrination, and presents the importance of Freire's education in Brazilian education.
\end{abstract}

Keywords: resistance counter-discourse; neo-conversationalism; Paulo Freire.

Para citar - (ABNT NBR 6023:2018)

FAVAL, Gabriela Costa; OLIVEIRA, Ivanilde Apoluceno de. Paulo Freire: contradiscurso e prática de resistência ao neoconservadorismo no cenário político e educacional brasileiro. Eccos - Revista Científica, São Paulo, n. 57, p. 1-15, e15407, abr./jun. 2021. Disponível em: https://doi.org/10.5585/eccos.n57.15407. 


\section{Introdução}

A partir de 2015, com o início da crise econômica e política, assiste-se, no Brasil, o ressurgimento de discursos que transformam Paulo Freire, mais uma vez, em inimigo do país. Frases como "chega de doutrinação marxista, basta de Paulo Freire" e "Paulo Freire será "abolido da educação brasileira" passaram a ser vistas nas manifestações de rua, na imprensa, aliadas a uma forte onda de intolerância que se alastrou e vem crescendo com a atual política neoconservadora instaurada no país.

Após as eleições de 2016 o ministro de Educação, Abraham Weintraub, tomou posse, fazendo a seguinte afirmação: "Se o Brasil tem uma filosofia de educação tão boa, Paulo Freire é uma unanimidade, por que a gente tem resultados tão ruins comparativamente a outros países? A gente gasta em patamares do PIB igual aos países ricos!” (HADDAD, 2019, p. 5).

A frase deixa clara a culpabilização de Paulo Freire pelos atuais fracassos educativos do país, sem que a pedagogia freireana tenha sido implantada de forma efetiva nas escolas brasileiras. Apresenta, mais uma vez, ataques à pedagogia de Freire, sendo acusada de proselitismo político em prol do comunismo. Essas críticas se fundamentam em discursos ideológicos de setores mais conservadores da sociedade brasileira, não tendo sustentação empírica.

É importante destacar que os ataques a Paulo Freire não podem ser analisados somente no âmbito pessoal, pois se configuram como ataques, sobretudo, ao campo do discurso crítico e democrático, que perpassa pelos conceitos de liberdade, criticidade, equidade e justiça social, entre outras. Conceitos que fazem parte do movimento democrático da sociedade, em busca de uma convivência social mais humana, ética e igualitária em termos dos direitos humanos.

Vemos, no século XXI, a reprodução do mesmo discurso de 1964, quando se deu a primeira perseguição político-ideológica a Paulo Freire, promovida pelo governo militar, sendo considerado comunista, inimigo de Deus e da pátria e seu método proibido e chamado de "subversivo", por fazer uma relação direta entre o processo educativo e a necessidade de compreensão da realidade social e econômica vivenciada pelos educandos.

Naquele momento, o programa implantado por Freire em Angicos foi visto pelos detentores do poder, não pela força pedagógica em alfabetizar em tempo récord, um grande número de pessoas jovens e adultas, e, sim, pelo efeito político desse processo de alfabetização, que viabilizou o direito ao voto deste segmento social, bem como pelo seu teor crítico, que possibilitou a essa população alfabetizada problematizar a situação de desigualdade social e 
educacional vigente no país. A proposta educacional de Paulo Freire permitiu que setores populares participassem mais conscientemente na política brasileira.

Assim, pela questão política o método freireano de alfabetização foi desligitimado e Paulo Freire banido, sendo obrigado a deixar o país por muitos anos, vivendo no exílio.

Nos anos de exílio, Freire retornaria ao Brasil sendo reconhecido como um dos mais importantes educadores do mundo, agrupando mais de 30 títulos de doutor honoris causa, em diversas universidades nacionais e estrangeiras e sendo nomeado presidente honorário de, pelo menos, 13 organizações internacionais (HADDAD, 2019). Em 1988, assumiu o cargo de Secretário de Educação do governo municipal de Luiza Erundina, nele permanecendo até 1991, sem, portanto, completar os quatro anos. A sua proposta educacional foi implantada na rede municipal de São Paulo, sendo destacada, também, a criação do Movimento de Educação de Jovens e Adultos - MOVA. Esta experiência, por meio do Movimento de Reorientação Curricular, chegou a ser realizada em alguns sistemas públicos de ensino do país: Maceió (AL), Dourados (MS), Angra dos Reis (RJ), São Paulo (SP), entre outros.

Em alguns sistemas municipais de ensino, foi implantada nas escolas a proposta de escola pública popular freireana: Escola Cidadã em Porto Alegre, Escola Plural em Belo Horizonte, a Escola Cabana em Belém, entre outras. Os estudos apontam que essas experiências foram práticas exitosas, o que evidencia a relevância da teoria de Paulo Freire nas práticas educativas escolares.

Estudo realizado pela Rede Freireana de Pesquisadores, com a participação de pesquisadores (as) do Pará sobre a experiência da educação de Paulo Freire no projeto Escola Cabana, na região metropolitana de Belém, aponta para os seguintes resultados exitosos:

a) A reorientação curricular, via tema gerador, implicou em mudanças conceituais e estruturais que, em sua prática, representaram os avanços e possibilidades da proposta.

b) As mudanças estruturais se efetivaram por meio da formação continuada de professores, da participação coletiva e diálogica dos (as) educadores(as) e do planejamento no ambiente escolar.

c) A criação da Hora Pedagógica (HP) possibilitou um tempo na escola destinado para a organização do trabalho pedagógico, propiciando momentos profissionalmente enriquecedores, que melhoraram a qualidade de ensino, sendo considerada uma conquista pelos (as) educadores (as). 
d) O trabalho interdisciplinar favoreceu mudanças nas relações interpessoais no plano político-pedagógico, contribuindo para uma maior interação entre escola, família e comunidade. A utilização do tema gerador favoreceu o processo de alfabetização de forma significativa e crítica. Contribuiu em relação aos educandos: mudança de postura no comportamento, aumento do interesse e concentração, valorização da autoestima, diminuição da agressividade, desenvolvimento de consciência crítica e uma aprendizagem mais efetiva da leitura e da escrita, na perspectiva do letramento.

e) Assim, a qualificação da aprendizagem dos educandos é oriunda, principalmente, da proposta metodológica que se torna mais dinâmica, lúdica e participativa por meio de uma gestão e produção coletiva do conhecimento.

Apesar de atualmente não estar presente nas escolas brasileiras como política educacional, o legado de Paulo Freire influenciou e ainda influencia a prática pedagógica de centenas de educadores (as), ao propor uma educação humanista e dialógica na qual a relação educador(a)/educando(a) seja uma ação de comunicação entre sujeitos de conhecimento, cujo processo dialógico possibilita a construção de uma relação democrática, na qual o (a) educador(a) ensina e aprende e o(a) educando(a) aprende e ensina. Não constitui um mero exercício mecânico de aprendizagem e com um único viés: ensinar-aprender. Este processo requer certa sensibilidade do(a) educador(a) para perceber a educação que se dá fora dos muros da escola, ou seja, as experiências de vida e saberes adquiridos nas práticas socioculturais dos(as) educandos(as), que precisam estar em diálogo com os saberes da escola. Além disso, coloca em prática uma ação educadora crítica, que possibilita a compreensão pelo(a) educando(a), de seu poder transformador, portanto, de ser sujeito de seu conhecimento e de sua história de vida e do desenvolvimento da sociedade em que está inserido(a).

Os ataques atuais a Paulo Freire não diferem dos ocorridos em 1964 e nem apresentam objetivos muito distintos. Surgem com o emergir de discursos de um segmento político-social elitista, insatisfeito com a aquisição de direitos e a ocupação de espaços sociais pelas massas populares e trabalhadores brasileiros. O agravante dos discursos atuais é a disseminação das chamadas fake news, notícias e informações espalhadas nas redes sociais e internet, sem a devida verificação das fontes e da veracidade dos fatos divulgados. Paralelamente a isso, avançam no Congresso Nacional propostas como o Projeto de Lei Escola Sem Partido que visam estabelecer uma mordaça à educação pública, travestidas de uma neutralidade educativa inexistente para reforçar discursos elitistas que objetivam a manutenção do status quo das elites brasileiras. 
Varela (2019, p. 2) afirma que: “... vive-se a falta de pensamento crítico, num contexto da pós-verdade em que as pessoas aceitam com facilidade as informações sem análise crítica”. Os avanços tecnológicos da comunicação global se tornaram, assim, instrumentos de apoio à nova onda de perseguições sofridas por Paulo Freire.

A questão norteadora deste artigo é: Quais as razões de Paulo Freire ser alvo de perseguições e críticas no atual contexto político?

Objetiva-se analisar, na atual conjuntura brasileira, o pensamento de Paulo Freire enquanto contradiscurso de enfrentamento e resistência, contra os ataques à sua pessoa e proposta educacional, esclarecendo os seus pressupostos educacionais, refutando as críticas infundáveis e apontando a sua importância no cenário educacional brasileiro.

Consiste em uma pesquisa bibliográfica que envolve não somente as produções de Paulo Freire, mas também de resultados de pesquisas sobre a educação freireana.

Apresenta-se, inicialmente, de forma contra-argumentativa as razões das perseguições ideológicas da educação de Paulo Freire e, posteriormente, o que caracteriza a educação freireana e a sua contribuição para a educação brasileira.

\section{Razões das perseguições ideológicas da educação de Paulo Freire}

Paulo Freire vem sendo alvo de perseguições e críticas por compreender que a educação é um ato político; pelo fato de ter influência de Marx e Gramsci no seu pensamento educacional, sendo considerado um marxista, e por criticar a moral e o discurso fatalista e imobilista da sociedade capitalista globalizada.

\section{a) A educação é um ato político}

A educação para Freire é uma ação política. Em relação ao caráter político da ação educativa, ressalta que não se deve confundir esse caráter político com o partidarismo sectário que impede a dialogicidade crítica. Explica que:

... enquanto seres humanos conscientes, podemos descobrir como somos condicionados pela ideologia dominante. Podemos distanciar-nos da nossa época. Podemos aprender, portanto, como nos libertar através da luta política na sociedade. Podemos lutar para ser livres, precisamente porque sabemos que não somos livres! É por isso que podemos pensar na transformação (FREIRE, 1986, p. 25).

Considera que a educação é política porque exige um posicionamento crítico do(a) educador(a) e do(a) educando(a) no contexto no qual ela se realiza. Por isso, o(a) professor(a) 
precisa se perguntar: a favor de quem e contra quem está educando? E a política, por apresentar uma educabilidade, precisa ser ensinada aos(às) educandos(as) de forma crítica e dialógica.

A sua percepção política da educação se deu a partir de suas experiências concretas, ou seja, das vivências de pobreza e de exclusão social desde a infância. Apesar de ter uma família estruturada, amorosa e ética, vivenciou situações de desigualdades sociais em face da pobreza que o levou a problematizar as situações de opressão da sociedade capitalista. "Graças à pobreza, aprendi, através da experiência, o que queria dizer classe social” (FREIRE, 1986, p. 40).

Questiona, também, a democracia que temos no país, que não exercita a autocrítica e nega a participação dos segmentos sociais na vida social. "Que democracia é esta que encontra para a dor de milhões de famintos, de renegados, de proibidos de ler a palavra, e mal lendo o seu mundo, razões climáticas ou de incompetência genética?” (FREIRE, 1993a, p. 25).

Por isso, defende uma educação crítica que viabilize "a passagem da transitividade ingênua à transitividade crítica" (FREIRE, 1967, p. 86), para que os sujeitos sociais tenham condições de lutar contra os "irracionalismos" dos quais estavam presos, com vistas à transformação social. Assim, considera ser imprescindível construir uma educação que possibilite a reflexão crítica sobre a realidade, visando alterar a condição social de pobreza e de opressão de determinados segmentos sociais, na busca da equidade social.

A educação, então, não pode ficar restrita a aspectos puramente técnicos, sendo necessária uma formação humanista, ética e política, com vistas à formação para o exercício da cidadania. Para Freire "a cidadania não é apenas o fato de ser um cidadão que vota [...] $\mathrm{O}$ conceito de cidadania vem casado com o conceito de participação, de ingerência nos destinos históricos e sociais" (2001, p. 129).

Em entrevista a Fernando Rossetti do jornal Folha de São Paulo Cotidiano, Paulo Freire chama atenção para a necessidade da formação política para se exercer a cidadania:

\footnotetext{
Nos anos 50 e 60 fui considerado um inimigo de Deus e da família, fui preso porque propunha que se alfabetizasse o país. Agora, nos anos 90, os industriais alfabetizam seus funcionários. Um cozinheiro precisa da técnica para desempenhar sua profissão. Mas exige também a capacitação política para exercer a cidadania, para intervir na sociedade. (FREIRE, 1996, p. 1).
}

Essa análise feita por Freire reflete os conceitos fundamentais de sua prática pedagógica e evidenciam seu posicionamento contrário à educação tecnicista neoliberal que, atualmente, se intensifica social e politicamente no Brasil.

Entre as medidas políticas atuais, projetos de lei vêm sendo apresentados ao Congresso brasileiro com "mudanças" necessárias para obter-se uma educação adequada aos interesses de 
uma elite neoconservadora e em nome da família brasileira. Aqui é imprescindível indagar-se: a qual família se refere esse discurso? A quem interessa essa educação centrada em livros didáticos, conteúdos fiscalizados, práticas restritas do educador, nas quais o pensamento do educador não pode ser manifesto sob nenhuma hipótese?

O Projeto de Lei no 7.180/2014, intitulado Escola Sem Partido, defendido por senadores e deputados ligados, em sua grande maioria, às bancadas religiosas, apresenta um discurso de neutralidade, contra a ideologia, porém tem o interesse político de:

a) Manter o discurso da neutralidade da ciência e a visão neoliberal de educação.

b) O olhar de não criticidade para o discurso eurocêntrico do conhecimento, que nega do ponto de vista epistemológico os saberes de culturas historicamente negadas, reforçando questões de gênero, classe, etnias, em termos de dominação.

c) Introduz a lógica implantada nos anos pós 64 do século passado de cumprimento de direitos e deveres com base na constituição brasileira, envolvendo, inclusive a ética como sinônimo de moral.

d) Contradiz o princípio da pluralidade de ideias e a liberdade de ensinar e aprender do professor e dos alunos, por ser uma medida que cerceia a liberdade de ensinar do professor utilizando um discurso de não ser político, sendo político.

O discurso de neutralidade educacional da Escola sem Partido é rechaçado por Freire (1986, p. 25) que afirma não haver neutralidade política e ideológica na educação: “Além de um ato de conhecimento, a educação é também um ato político. É por isso que não há pedagogia neutra”. Desta forma, não há neutralidade política e ideológica do Estado e toda política e prática educativa tem uma concepção de educação, que pode ser reprodutivista ou transformadora.

Freire (1986, p. 49) explica que:

[...] do ponto de vista da classe dirigente, das pessoas que estão no poder, a tarefa principal da educação sistemática é reproduzir a ideologia dominante [...] Dialeticamente, há, no entanto, outra tarefa a ser cumprida, qual seja, a de denunciar e de atuar contra a tarefa de reproduzir a ideologia dominante. (Grifo do autor).

Assim, há um posicionamento político do(a) educador(a), cuja tarefa é viabilizar aos(às) educandos(as) uma leitura crítica de mundo, apreendendo a razão de ser dos fatos.

Segundo Freire, a educação requer ações coletivas de transformação social com o intuito de desenvolver a real democracia, que requer um constante dialogar com o outro, um revisar e 
criticizar os próprios achados e um flexibilizar de consciências, permitindo substituir a passividade pela participação e ingerência crítica dos sujeitos.

A educação é definida por Freire (1967, p. 96) como “... um ato de amor, por isso, um ato de coragem", na qual são necessários o debate, a análise da realidade e a discussão criadora. Educar exige uma posição humanista e ético-política por parte dos sujeitos educacionais. Assim, quando o (a) educando (a) se posiciona, cria seus próprios conceitos a respeito do que vivencia, se analisa dentro deles e se percebe integrante de uma determinada realidade, que pode ser por ele (a) alterada. A educação freireana fornece aos(às) educandos(as) as diretrizes educacionais que lhe possibilitam refletir e perceberem-se construtores(as) do mundo, por meio da produção e construção do conhecimento.

\section{b) A influência de Marx e Gramsci no pensamento educacional de Paulo Freire}

Paulo Freire apresenta, em seu pensamento educacional, influência do Humanismo Cristão, do Existencialismo, do Personalismo, da Fenomenologia e do Marxismo. Entretanto, a perseguição a ele pauta-se no discurso que ele é marxista.

Freire em entrevista a Leite afirma: "não fui às classes oprimidas por causa de Marx. Fui a Marx por causa delas. O meu encontro com elas é que me fez encontrar Marx e não o contrário" (1979). Explica que não vê nenhuma contradição à sua opção cristã pretender uma sociedade que não se funda na exploração de uma classe por outra. Destaca que tanto a sua posição cristã quanto a sua aproximação a Marx se efetivou, não no nível intelectualista, mas sempre referida ao concreto, isto é, pelas suas condições econômicas e sociais de pobreza, de uma realidade social de classes.

O pensar a partir da experiência, da realidade concreta está presente nos escritos de Paulo Freire:

\footnotetext{
A experiência das dificuldades no estudo em virtude da fome, ensinou-o a estabelecer a relação entre classe social e conhecimento; a experiência com os trabalhadores o levou à compreensão mais radical da educação: a humildade em relação ao saber, a aprender com o trabalhador, a não dicotomizar o conhecimento menos rigoroso do mais rigoroso e a percepção da não inferioridade da linguagem popular e, por fim, o exílio permitiu-lhe a compreensão da política na educação (1986, p. 40-42).
}

Um ponto de aproximação entre o Cristianismo e o Marxismo, explicitado pelo próprio Freire, é a atitude de não passividade de homens e mulheres frente à opressão. Freire é a favor de uma educação crítica, dialógica, não autoritária e não reacionária. Por isso, faz critica a todos aqueles que tendem a transmitir verdades, sem criticidade. Critica o processo de autoritarismo 
e de alienação presente no discurso educacional e nas práticas escolares "bancárias", seja da classe dominante ou não:

\begin{abstract}
Algumas pessoas de esquerda estão religiosamente convencidas de que receberam uma procuração de Deus, apesar de não acreditarem em Deus, para salvar os estudantes, para salvar o povo. Acreditam ter a verdade nas mãos, e ser sua tarefa caminhar pelo mundo como Peregrinos da Revolução, sem discutir a "verdade", mas simplesmente colocando-a dentro do maior número possível de cabeças (FREIRE, 1986, p. 102).
\end{abstract}

Pensa, então, que ensinar não é depositar conhecimentos na cabeça dos(as) educandos(as) sem problematizá-los do ponto de vista ideológico e político. Por isso, critica a pedagogia tradicional, considerando-a além de "Bancária" uma "Pedagogia da Resposta", já que há uma transmissão de conteúdos prontos e acabados pelo(a) professor(a) e o caráter assistencial e de adaptação que a educação se reveste quando se torna um processo de "transmissão" mecânica do conhecimento "depositado" pelo(a) professor(a) ao(a) aluno(a).

Em contraposição à Pedagogia da Resposta propõe Freire a Pedagogia da Pergunta, cuja tarefa do(a) professor(a) é problematizar aos(às) educandos(as) o mundo que os(as) mediatiza; é estimular a curiosidade e o ato de perguntar no processo educativo.

Freire analisa a educação como processo de conscientização crítica, sendo o sujeito capaz de compreender a razão de ser dos fatos, superando a apreensão ingênua da realidade social. Desta forma, a educação para Paulo Freire constitui um ato de "conscientização crítica" , de "desmitologização" em que se desoculta a ideologia da classe dominante e, assim, se constitui em ato de "libertação".

\title{
c) Crítica a moral e ao discurso fatalista e imobilista da sociedade capitalista globalizada
}

Paulo Freire, em sua Pedagogia da Indignação, ressalta o fato de vivermos em um contexto econômico, político e social globalizado excludente, de violência e desrespeito à vida, aos direitos humanos e à natureza. Critica a moral capitalista por ser uma sociedade que é regida pela lógica do mercado, apresentando um discurso moral individualista, do "cada-um-por-si", do "salve-se-quem-puder" e do "vale-tudo" (FREIRE, 2000). Uma moral que tem como fim o "lucro" e os "bens materiais", adquirindo estes um sentido de "felicidade". Moral em que prevalece o "ter" sobre o "ser sujeito", apesar de se necessitar ter para ser; o "egoísmo" sobre a "solidariedade" e o "eu" sobre o "outro", o "não-eu”, que se apresenta negado e coisificado.

Freire propõe, então, a Ética universal do ser humano, que tem como princípio fundamental a vida. Ética que pressupõe uma luta pelos direitos do ser humano de viver com dignidade e liberdade. Ética comprometida com os excluídos, os oprimidos, “os condenados da 
Terra", fundamentada no respeito às diferenças. Ética que condena a exploração, a discriminação de homens e mulheres e o desrespeito à vida humana.

Ética que pressupõe novos valores gestados, não em práticas sociais individualistas, como na "ética do mercado", mas em experiências de solidariedade e ações coletivas dialógicas. Ética inseparável da prática educativa. Na visão de Freire (2007, p.65) “... a prática docente, especificamente humana, é profundamente formadora, por isso, ética”. Os (as) educadores(as) têm de lutar pela ética vivendo-a em sua prática educativa, na maneira de lidar com o conteúdo e na forma de relacionar-se com os discentes. A educação na visão de Freire (2007, p. 33 e 21) não pode ser treinamento técnico, mas formadora, sendo os conteúdos relacionados à formação moral dos educandos. "Educar é substancialmente formar" e "ensinar não é transferir conhecimento, mas criar as possibilidades para a sua própria produção ou a sua construção".

A educação freireana é comprometida ética e politicamente com a luta pela superação da discriminação e da exclusão na sociedade e na escola. Um dever ético do(a) professor(a) enquanto sujeito de uma prática educativa é o respeito à autonomia, à dignidade e às diferenças de ideias e de posições de seus educandos e educandas. Consiste em uma educação da pessoa compreendida na integralidade do seu ser como indivíduo e cidadão, objetivando uma vivência social mais humana, justa e solidária.

Freire critica a ideologia fatalista do discurso neoliberal que imobiliza o ser humano na busca de ser mais e na construção histórica de sua autonomia:

\begin{abstract}
A ideologia fatalista, imobilizante, que anima o discurso neoliberal anda solta no mundo. Com ares de pós-modernidade, insiste em convencer-nos de que nada podemos contra a realidade social que, de histórica e cultural, passa a ser ou a virar "quase natural". Frases como "a realidade é assim mesmo, que podemos fazer? Ou "o desemprego no mundo é uma fatalidade do fim do século" expressam bem o fatalismo desta ideologia e sua indiscutível vontade imobilizadora (FREIRE, 2007, p. 20).
\end{abstract}

Problematiza, neste discurso, a visão ideológica de impossibilidade de mudar o mundo, que se configura na "inviabilização do possível” e a história como determinação. Destaca: "é percebendo e vivendo a história como possibilidade que experimento plenamente a capacidade de comparar, de ajuizar, de escolher, de decidir, de romper” (FREIRE, 2000, p. 57).

Freire, então, nos alerta para o caráter ideológico da educação, que nos torna "míopes", aceitando passivamente o que vemos e ouvimos. Explica que a ideologia "tem que ver diretamente com a ocultação da verdade dos fatos, com o uso da linguagem para penumbrar ou opacizar a realidade ao mesmo tempo em que nos torna 'míopes"' (FREIRE, 2007, p. 125).

Miopia que acomoda homens e mulheres diante do discurso fatalista do neoliberalismo, que ressalta a globalização econômica como algo inevitável e não como "um momento do 
desenvolvimento econômico submetido, como toda produção econômica capitalista, a uma certa orientação política ditada pelos interesses dos que detêm o poder” (FREIRE, 2007, p. 126). Discurso que nos faz acreditar, ainda, que as elites e suas propostas sociais e educacionais são as melhores soluções para as desigualdades.

Esse discurso de superioridade da elite dominante é tratado por Dussel (1994) no que denomina de "mito da modernidade", por meio do qual a dominação dos ditos civilizados sobre os considerados menos evoluídos torna-se imprescindível para o avanço das sociedades. $\mathrm{O}$ “outro", no pensamento do dominador, é visto como "o mesmo", atrasado em sua evolução, culpado de sua imaturidade evolutiva e, portanto, precisa ser "civilizado", seja qual for o custo, inclusive o da força. Desta forma, toda violência usada no intuito de modernizar esse outro se torna justificável e necessária para o avanço da sociedade no âmbito moral e cultural.

O discurso ideológico da globalização configura-se para Freire como um instrumento de manutenção das diferenças sociais; por este motivo, alerta: “... uso dos discursos ideológicos que anestesiam a mente e que não podem ser ouvidos sem um mínimo de resistência crítica" (2007, p. 50). Discurso determinante da história, "sem ideologia", que imobiliza homens e mulheres como seres de escolhas e de decisões e a própria democracia. Por isso, esclarece Freire que:

... em lugar da decretação de uma nova História sem classes, sem ideologia, sem luta, sem utopia, e sem o sonho, o que a cotidianidade mundial nega contundentemente, o que temos a fazer é repor o ser humano que atua, que pensa, que fala, que sonha, que ama, que odeia, que cria e recria, que sabe e que ignora, que se afirma e que se nega, que constrói e destrói, que é tanto o que herda quanto o que adquire, no centro de nossas preocupações (1993a, p. 14).

Ao resistir criticamente aos discursos ideológicos o educador se mantém aberto às diferenças, respeitando as opções contrárias, sem a intenção de conquistá-las e recusando posições dogmáticas que tendem a mascarar ou ocultar as ideologias.

A educação se apresenta, então, como um processo de comunicação entre sujeitos. É um processo de busca e, por isso, requer sujeitos curiosos e ávidos pelo conhecimento de si mesmos e do mundo. Requer uma prática em favor da autonomia dos(as) educandos(as) e educadores(as). O respeito à autonomia dos sujeitos educacionais é, para Freire (2000), um imperativo ético e não deve ser concedido como uma espécie de favor. Ela é, antes de tudo, um exercício da dialogicidade em que, conscientes de sua incompletude, os sujeitos aprendem e crescem em suas diferenças, tornando-se radicalmente éticos. Por isso, para Paulo Freire, tentar posicionar-se de forma neutra no processo educativo é claramente, invisibilizar a especificidade dos educandos, negando-se a discuti-la e problematizá-la, constituindo-se em uma ruptura ética 
e moral do dever educador de lutar contra as discriminações sociais por fatores de classe, étnia, gênero, idade, entre outras.

Porém, o que se evidencia no contexto atual é, justamente, o contrário a essa ação humanista e política proposta por Freire. A elite quer retomar seu papel de direcionadores das massas populares, como afirma Le Bon (apud CARVALHO, 1998, p. 43-44) ao analisar a educação brasileira na década de 20 e a relação "povo-elites" e os movimentos de rua como manifestações de "homens-massa", incapazes de refletir e raciocinar, mas habilitados para agir. Segundo o autor, as elites assumiam, então, o papel de "guias" ou "condutoras" das multidões e essa condução era feita por sugestão, produzida também "pela educação entendida como processo de transferência do consciente para o inconsciente de valores e atitudes, pela formação de hábitos". O projeto educacional idealizado nos anos 20 do século passado se deu no âmbito da formação de uma nacionalidade e propunha a escola como "instância de homogeneização cultural por via da inseminação de valores e da formação de atitudes patrióticas”. Nos discursos políticos atuais observamos o mesmo nacionalismo e a mesma homogeneização cultural de cunho moralista e patriótico.

\section{A importância de Paulo Freire para a educação brasileira}

Paulo Freire tem uma importância histórica na educação brasileira, cujo inicio foi nos anos 50 do século $\mathrm{XX}$, com a educação popular, trazendo para debate o modelo de escola bancária excludente e a proposta de uma educação popular, que tem na educação de jovens e adultos o seu suporte teórico-metodológico. Nos anos 80 do mesmo século, o seu pensamento educacional passa a ser tratado como pedagogia progressista crítica, ampliando para todos os níveis e modalidades de ensino. Atualmente, Paulo Freire vem sendo referenciado no debate da interculturalidade crítica e no pensamento descolonial na América Latina.

O seu legado educacional se estende cada vez mais em todo o mundo e, no Brasil, por meio de grupos e redes de pesquisas, cátedras, institutos e práticas educacionais escolares e em diferentes contextos socioeducativos como centros comunitários, hospitais, entre outros.

Oliveira e Santos destacam que na América Latina:

... o Brasil é o que possui maior número de estudos/ações educacionais com base em Paulo Freire, considerando os grupos de pesquisas cadastrados no CNPq, bem como a importância do seu trabalho educacional no Brasil, no âmbito da educação popular, de jovens e adultos, nos movimentos sociais, no campo da pedagogia, nas práticas institucionais, entre outros (2018, p.109). 
As autoras identificaram, no Brasil, oito Cátedras Paulo Freire, um Instituto e quarenta e seis grupos de pesquisas, sendo trinta e nove cadastrados no Diretório do CNPq. Paulo Freire vem sendo estudado por meio de grupos de pesquisas, tem sido referência em práticas educativas escolares e socioeducativas em diferentes contextos, no processo de formação continuada de professores e em atividades extensionistas, como os eventos e em publicações.

Nessas ações, o que predomina e é valorizado do pensamento educacional de Paulo Freire é o seu caráter humanista e ético, engajado politicamente na luta das pessoas que sofrem opressão social por fatores de classe, etnia, gênero, entre outras.

A sua educação é humanista porque pretende a humanização de homens e mulheres, na medida em que rejeita toda forma de manipulação humana e dimensiona o ser humano como o sujeito da educação. É humanista, também, porque se dimensiona pela articulação entre o existencial, o político e o ético. A educação é considerada instrumento de desalienação e de libertação de homens e mulheres oprimidos que, ao refletirem sobre a sua condição de explorado, se engajam numa luta para a transformação social e sua libertação da opressão. Educação que eticamente se indigne com as discriminações e as injustiças sociais, compromissada com o sonho ético e político de uma sociedade e de uma escola democrática.

Assim, há o sonho de se ter uma sociedade mais justa, mais humana, mais solidária e menos violenta. Como ele afirma:

\footnotetext{
Sonhar não é apenas um ato político necessário, mas também uma conotação da forma histórico-social de estar sendo de mulheres e homens. Faz parte da natureza humana que, dentro da história, se acha em permanente processo de tornar-se [...] Não há mudança sem sonho como não há sonho sem esperança [...].A compreensão da história como possibilidade e não determinismo... seria ininteligível sem o sonho, assim como a concepção determinista se sente incompatível com ele e, por isso, o nega (FREIRE, 1993b, p. 91-92).
}

Educação que problematiza a realidade social, estimulando o diálogo, a curiosidade e o ato de perguntar dos sujeitos na ação educativa, estando comprometida com a possibilidade histórica de mudança social, fundamentada em ações educativas concretas, que valorize a pessoa humana e respeite a autonomia de homens e mulheres, enquanto sujeitos do conhecimento, da história e da cultura.

\section{Considerações finais}

Paulo Freire, no atual contexto político brasileiro, vem sendo perseguido, criticado e acusado pelas mazelas da educação brasileira. Críticas sem consistência argumentativa, pautadas em discurso nacionalista e neoconservador ideologicamente construído, que atentam 
contra toda a historicidade construída por Paulo Freire na educação em âmbito internacional e reconhecida no País, ao ser agraciado como Patrono da Educação Brasileira.

É olhado de forma negativa por trazer para debate a educação como ato político, ter em seus fundamentos teóricos Marx e Gramsci, sendo considerado por alguns como marxista e por fazer crítica, na perspectiva ética, ao discurso fatalista e imobilizante da sociedade capitalista globalizada. Ao focarem nestes aspectos, há um olhar reducionista do pensamento educacional de Paulo Freire, centrado nas questões ideológicas (no mal sentido da palavra), além de interpretações equivocadas sobre a própria dimensão política do seu pensamento educacional, sendo associada ideologicamente à política partidária.

Paulo Freire deixou um legado internacional, estando presente em todos os continentes do mundo e, no Brasil, tem sido pesquisado e sido referência a práticas educativas em todos os níveis de ensino e em diferentes contextos educacionais. É, portanto, parte inerente da história da educação brasileira, sendo valorizadas as suas diretrizes humanistas, éticas e políticas educacionais, com vistas à construção de uma sociedade mais justa e com equidade social.

Há necessidade, portanto, de reconhecer-se o pensamento educacional de Paulo Freire como de resistência ao discurso neoconservador, bem como a sua contribuição para a educação brasileira desde os anos 50 do século XX na educação popular e na educação de jovens e adultos, nos anos 80 do mesmo século por meio da pedagogia humanista libertadora e, finalmente, nos anos 90 do século passado e 2000, no debate sobre interculturalidade crítica e descolonialidade no contexto educacional brasileiro e na América Latina.

\section{Referências}

BRASIL. Projeto de Lei $\mathrm{N}^{\circ}$ 7180. Escola sem partido. Brasilia. 2014. Disponível em: https://www.programaescolasempartido.org/projeto. Acessado em: 23/09/2019

CARVALHO, Marta Maria Chagas de. Molde nacional e forma cívica: higiene, moral e trabalho no projeto da Associação Brasileira de Educação (1924 - 1931). Bragança Paulista, SP: EDUSF, 1998.

DUSSEL, Enrique. El encubrimiento del otro: hacia el origen del mito de la modernidade. 3. ed., Quito-Equador: ABYA-YALA, 1994.

FREIRE, Paulo. Pedagogia da autonomia: saberes necessários à prática educativa. 36 ed.. São Paulo: Paz e Terra, 2007.

FREIRE, Paulo. Pedagogia dos sonhos possíveis. São Paulo: UNESP, 2001.

FREIRE, Paulo. Pedagogia da indignação: cartas pedagógicas e outros escritos. São Paulo: UNESP, 2000. 
FREIRE, Paulo. Política e educação. São Paulo: Cortez, 1993ª (Coleção Questões da nossa Época).

FREIRE, Paulo. Pedagogia da esperança: um reencontro com a Pedagogia do oprimido. São Paulo: Paz e Terra, 1993b.

FREIRE, Paulo; SHOR, Ira. Medo e ousadia: o cotidiano do professor. São Paulo: Paz e Terra, 1986.

FREIRE, Paulo. Conscientização: teoria e prática da libertação: uma introdução ao pensamento de Paulo Freire. 4 ed., São Paulo: Moraes, 1980.

FREIRE, Paulo. Educação como prática de liberdade. Rio de Janeiro: Paz e Terra, 1967.

HADDAD, Sérgio. Explicação sobre os ataques de Bolsonaro a Paulo Freire. Blog "O outro lado da notícia. Disponível em: outroladodanoticia.com.br/2019/04/14/explicacao-sobre-osataques-do-bolsonarismo-a-paulo-freire/ Acessado em: 26/05/2019

LEITE, Ligia C. Encontro com Paulo Freire. In: Educação e Sociedade. São Paulo: Cortez; Autores Associados n. 3, 1979, p.

OLIVEIRA, Ivanilde Apoluceno de; SANTOS, Tânia Regina Lobato dos Santos. Paulo Freire na América Latina e nos Estados Unidos: Cátedras e Grupos de Pesquisas. Revista Educação em Questão, Natal, v. 56, n. 48, p. 106-139, abr./jun. 2018.

OLIVEIRA, Ivanilde Apoluceno de (Org). Relatório da pesquisa: "presença de Paulo Freire na Escola Cabana (1997 A 2004)”. Belém-Pará: NEP/UEPA, 2012.

ROSSETTI, Fernando. Paulo Freire critica ensino "neo-liberal". Folha de São Paulo, 07/10/96. Disponivel em: https://www1.folha.uol.com.br/fsp/1996/10/07/cotidiano/3.html Acessada em: 26/07/19.

VARELA, Florenço Mendes. Professores estrangeiros exaltam Paulo Freire, atacado pelo governo. Rede Brasil Atual - (Art.) Revista Educação. RBA, 21/04/19. Disponível em: https://www.redebrasilatual.com.br/educacao/2019/04/professores-estrangeiros-exaltampaulo-freire-atacado-pelo-governo/ Acessado em: 29/08/19. 